\title{
Maternal vitamin D deficiency: A Culprit for Hypocalcaemia Induced Myocardial Failure in a Four-Month Old Infant: A Case Report From Tikur Anbessa Specialized Hospital, Ethiopia
}

\author{
Tamirat Moges ${ }^{1 *}$, Yemisirach Shiferaw ${ }^{2}$, Tigist Heye ${ }^{3}$
}

\footnotetext{
OPEN ACCESS

Citation: Tamirat Moges, Tigist Heye, Yemisirach Shiferaw. Maternal vitamin D deficiency: A Culprit for Hypocalcaemia Induced Myocardial Failure in a Four-month old Infant: A Case Report From Tikur Anbessa Specialized Hospital, Ethiopia. J Health Sci 2017;27(3):299. doi: http://dx.doi.org/10.4314/ejhs.v27i3.12

Received: September 11, 2016

Accepted November 22, 2016

Published: May 1, 2017

Copyright: (c) 2017 Tamirat M., et al. This is an open access article distributed under the terms of the Creative Commons Attribution License, which permits unrestricted use, distribution, and reproduction in any medium, provided the original author and source are credited. Funding: Nil

Competing Interests: The authors declare that this manuscript was approved by all authors in its form and that no competing interest exists.

Affiliation and Correspondence:

${ }^{1}$ Department Pediatrics, School of health Sciences, Addis Ababa

University, Ethiopia

${ }^{2}$ Department Pediatrics, College of Health Sciences, Addis Ababa University, Ethiopia

${ }^{3}$ Department Pediatrics, School of

health Sciences, Addis Ababa

University, Ethiopia

*Email:

tamirataklilu09@gmail.com/mogest98

@ yahoo.com
}

\begin{abstract}
BACKGROUND: A rare but reversible cause of dilated cardiomyopathy occurs in infants born to vitamin $D$ deficient mothers due to hypocalcaemia.

CASE REPORT: We report a case of dilated cardiomyopathy due to hypocalcaemia secondary to maternal vitamin $D$ deficiency in an infant presented with seizure disorder and heart failure. This was a four-month old female infant with respiratory distress and acute heart failure. The cause of her cardiac failure was dilated cardiomyopathy. Concomitant community acquired pneumonia was diagnosed on chest $X$ ray. Despite treatment, the infant's clinical condition worsened. The mother was found to be housebound, dark skinned and veiled while going outside of home. Laboratory studies revealed hypomagnesaemia and hypocalcaemia. The vitamin $D$ levels of both the infant and the mother were found to be low. The infant was treated for the deficiency state until her cardiac condition fully recovered.

CONCLUSION: This case report demonstrated the direct relationship between maternal vitamin $D$ deficiency and the infant's acute heart failure. It also highlighted the importance of vitamin $D$ supplementation during pregnancy in order to prevent the cardiac complication of maternal vitamin $D$ deficiency in the infants.

KEYWORDS: Dilated cardiomyopathy, Hypocalcaemia, vitamin D, cardiac failure
\end{abstract}

\section{INTRODUCTION}

Hypocalcaemia is a rare, yet reversible cause of dilated cardiomyopathy in infants born to vitamin D deficient mothers. Calcium is essential for the initiation of excitation-contraction coupling via influx through L-type calcium channels (1). Calcium determines contractibility by expediting the tension developed between actin and myosin filaments via the troponin-tropomyosin complex. Reduced level of calcium leads to diminished reaction in these energy generating chemicals leading to cardiac dysfunction. 
Maternal vitamin D deficiency induced hypocalcaemia resulting in dilated cardiomyopathy has been reported in few occasions (2). We report a case of dilated cardiomyopathy due to hypocalcaemia secondary to maternal vitamin D deficiency in an infant, presented with seizure and cardiac failure.

Although acute heart failure in relation to severe rickets was reported previously from the same setting, isolated dilated cardiomyopathy in the absence of rickets in the setting of vitamin D deficiency was not reported from Ethiopia at least to our knowledge (3). In this case report, the clinical features and possible explanations of the presentations were discussed.

\section{CASE REPORT}

A four-month old female infant was referred to our emergency unit after a two weeks' history of cough, fever and fast breathing. After visiting different local health institutions, she was diagnosed to have community acquired pneumonia on the basis of chest X-ray findings. Alerted by detection of a murmur, the primary physician suspected heart disease and ordered transthoracic echocardiographic test which showed dilated cardiomyopathy. After initiation of medication for pneumonia and cardiac failure at a private hospital, the doctors referred the patient to our institution. On evaluation of the history at our emergency unit, the baby had history of interrupted feeding but not perspiration. She was vaccinated for age and was fed on exclusive breast-feeding. Even though her birth time coincided with beginning of the rainy season, the parents claimed that she was exposed to sunshine appropriately. She was born to a 28 year-old ParaII mother at term by caesarean section for breech presentation. The mother reported loss of her firstborn baby at the age of three months due to pneumonia. The mother was a dark skinned lady who gave history of poor sun exposure in herself for about five years period as she was living in an apartment as a maid. She got veiled whenever she went out in a sunny day which she did rarely. On examination of the patient, we found that she had signs of respiratory distress despite normal auscultatory finding of the lung fields. The arterial pulses were weak but palpable in all pulse areas. The neck veins looked distended. Apical beat was felt at the 5th intercostal space lateral to the mid clavicular line. S1 and S2 were heard with no P2 accentuation. There was Grade III/VI pan systolic murmur best heard at the apex radiating to the left axilla. There was S3 gallop. The liver was palpated $5 \mathrm{~cm}$ below the right costal margin with total vertical span of $7 \mathrm{~cm}$ (enlarged for age). There was bilateral pedal edema.

Table 1 shows the summary of anthropometric measurements and vital signs. After cardiologic consultation, treatment was reinitiated for pneumonia and congestive heart failure at our emergency ward with furosemide $1 \mathrm{mg} / \mathrm{kg}$ intravenous 12 hourly, Captopril orally $2 \mathrm{mg}$ every 12 hour, Digoxin $0.0625 \mathrm{mg}$ per os once daily, and Ceftriaxone 260mg intravenous every 12 hour. On the second day of her admission to the emergency ward, the infant developed episodes of convulsions characterized by tonic clonic jerking movement of the extremities associated with upward eye movement. Symptomatic seizure secondary to meningitis or electrolyte imbalance was considered. Blood sample was sent for analysis. While we were waiting for the lab results, antibiotic dose was made anti-meningeal. Subsequently, the infant went into repeated cardio-respiratory arrest. After cardio-respiratory resuscitation, the patient was transferred to pediatric ICU for mechanical ventilation. The result of laboratory investigation is in Table 2. Imaging modality was also determined and showed the following results. Chest X-ray showed gross cardiomegaly with right upper lobe opacity and increased pulmonary vascularity. The infant's wrist X-ray was reported as normal. Electrocardiography was reported as sinus rhythm, Rate $=166 \mathrm{bpm}, \mathrm{PR}$ - interval $=60 \mathrm{~ms}$, $\mathrm{QTc}=465 \mathrm{~ms}$ and $\mathrm{R} / \mathrm{S}$ progression less than 1 . Table 3 shows the pre- and post-treatment transthoracic echocardiographic profiles of the patient.

Maternal serum vitamin D level was determined to be $10.4 \mathrm{ng} / \mathrm{mL}$ (normal value 20$100 \mathrm{ng} / \mathrm{ml})(\mathrm{ICL})$. Having confirmed hypocalcaemia and hypomagnesaemia, we initiated treatment for the infant with $10 \%$

DOI: http://dx.doi.org/10.4314/ejhs.v27i3.12 
Calcium gluconate $7 \mathrm{ml}$ in $15 \mathrm{ml} \mathrm{D} / \mathrm{W}$ over 15

$0.7 \mathrm{ml}$ in $70 \mathrm{ml} \mathrm{N} / \mathrm{S}$ over 30 minutes every 8 hours; minutes every six hours; Magnesium sulphate and Vitamin D 600,000 IU IM stat dose.

Table 1: Anthropometry and vital sign profile at admission.

\begin{tabular}{lll}
\hline Anthropometry & Result & Normal range \\
\hline Weight- & $7 \mathrm{~kg}$ & (50th- 85th centile WHO growth curve) \\
Length- & $59 \mathrm{~cm}$ & (b/n 3rdth-15th centile on WHO) \\
Head Circumference- & $43 \mathrm{~cm}$ & $($ at 75th centile on CDC growth chart) \\
Respiratory rate- & $54 \mathrm{breath} /$ minute, & $(30-50 \mathrm{breath} /$ minute $)$ \\
Apical Heart Rate- & $140 \mathrm{bpm}$ & $(80-160 \mathrm{bpm})$ \\
Temperature (rectal)- & $37.9 \mathrm{oc}$, & $(36.6-38 \mathrm{oC})$ \\
& $88 / 49 \mathrm{mmHg}$, & $(88-101 \mathrm{mmHg}$ - systolic) \\
Blood pressure measurement ${ }^{\wedge}{ }^{\wedge}$ & (lying left arm arm) & $(50-76 \mathrm{mmHg}$ - diastolic)
\end{tabular}

Table 2: Laboratory test profile

\begin{tabular}{lll}
\hline Lab test & Result & reference range $\$$ \\
\hline WBC & 7,820, cells/mcl & $3.5-10.5 \mathrm{cell} / \mathrm{s} / \mathrm{mcL}$ \\
$\mathrm{Hgb}$ & $10.2 \mathrm{gm} / \mathrm{dl}$, & $12.0-15.5 \mathrm{gm} / \mathrm{dl}$ \\
$\mathrm{Hct}$ & $35.1 \%$, & $34.9 \%-44.5 \%$ \\
$\mathrm{MCV}$ & $80 \mathrm{fl}$, & $75-95 \mathrm{fl}$ \\
Platelet count & $430,000 / \mathrm{mcl}$. & $150,000-450,000 / \mathrm{mcL}$ \\
Ionized calcium & $2.28 \mathrm{mg} / \mathrm{l}$ & $4.5-5.6 \mathrm{mg} / \mathrm{dl}$ \\
Magnesium & $1.5 \mathrm{mg} / \mathrm{l}$ & $1.9-2.5 \mathrm{mg} / \mathrm{dl}$ \\
Potassium & $3.9 \mathrm{mmol} / \mathrm{l} ;$ & $3.5-5.1 \mathrm{mmol} / 1$ \\
Sodium & $133 \mathrm{mmol} / \mathrm{l} ;$ & $136-145 \mathrm{mmol} / 1$ \\
Chloride & $112 \mathrm{mmol} / \mathrm{l} ;$ & $98-107 \mathrm{mmol} / 1$ \\
Phosphorus & $7.3 \mathrm{mg} / \mathrm{l}$. & $4.0-7.0 \mathrm{mg} / 1$ \\
BUN & $15 \mathrm{mg} / \mathrm{l}$, & $15-48 \mathrm{mg} / 1$ \\
Creatinine & $0.5 \mathrm{mg} / \mathrm{l}$ & $0.6-1.1 \mathrm{mg} / \mathrm{l}$. \\
SGPT & $32 \mathrm{U} / \mathrm{L}$ & $<42 \mathrm{u} / \mathrm{L}$ \\
SGOT & $102 \mathrm{U} / \mathrm{L}$ & $<37 \mathrm{u} / \mathrm{L}$ \\
ALK phosphatase & $80 \mathrm{u}$ & Normal. \\
$*$-25hydroxyvitaminD & $6.0 \mathrm{ng} / \mathrm{mL}$ & $30-40 \mathrm{ng} / \mathrm{mL}$ \\
Serum Parathyroid level & $91.8 \mathrm{pg} / \mathrm{ml}$ & $15-65 \mathrm{pg} / \mathrm{mL}$. \\
& & \\
\hline
\end{tabular}

\$-referrence rage for the lab,*- Chemiluminescent Micro particle Immunoassay (CMIA); International clinical laboratories(Medpharm holdings Africa Ltd company). 1,25(OH)2-vitamin D -1,25 dihydroxy vitamin D,MDmedical doctor, SGPT-serum gluthamic pyruvic transaminase, SGOT-Serum Gluthamic Oxaloacetic transaminase, ICU-Intensive care unit,IV-intravenous, S3- third heart sound,PO- per OS,Bpm-Beat per minute,PR-P-R interval, QTc- Corrected QT interval, R/S - The ratio of R wave to S wave, LV-Left ventricle, S1-First heart sound, S2-Second heart sound , P2-Pulmonary heart sound, IU - International unit,IM-intramuscular

DOI: http://dx.doi.org/10.4314/ejhs.v27i3.12 
After 12 days of treatment, the serum electrolyte abnormalities were corrected to normal level. Subsequent echocardiographic examination before discharge revealed significant improvement from the left ventricular (LV) EF of $37 \%$ at admission to $\mathrm{LV} \mathrm{EF}$ of $56 \%$ at discharge. She was discharged after three weeks of hospital stay to have subsequent cardiologic follow-up.

Follow-up echocardiographic evaluation showed LV ejection fraction of above $60 \%$. Mitral regurgitation disappeared. There was no seizure or localized neurologic deficit observed at least in the first six months of follow-up. Written informed consent was obtained from the parents for publication of this case report. The Research and Promotion Committee (DRPC) of the Department of Pediatrics and Child Health was also notified about the plan to publish this case report.

Table 3: Pre- and Post treatment transthoracic echocardiographic profile.

\begin{tabular}{|c|c|c|c|}
\hline $\begin{array}{l}\text { Laboratory } \\
\text { Profile }\end{array}$ & $\begin{array}{l}\text { Pre treatmet } \\
\text { result }\end{array}$ & $\begin{array}{l}\text { Post } \\
\text { treatment }\end{array}$ & Reference value $€$ \\
\hline $\begin{array}{l}\text { Left ventricle } \\
\text { Ejection fraction (LVEF) }\end{array}$ & $37 \%$ & range* $(55 \%-66 \%)$ & $45 \%-90 \%$ \\
\hline $\begin{array}{l}\text { Left ventricle } \\
\text { Fractionalshortening }\end{array}$ & $17 \%$ & range $(28-37 \%)$ & $28 \%-41 \%$ \\
\hline Left atrial diameter & $33 \mathrm{~mm}$ & $10-12 \mathrm{~mm}$ & $12-15 \mathrm{~mm}$ \\
\hline $\begin{array}{l}\text { Left ventricular end } \\
\text { diastolic diameter }\end{array}$ & $34 \mathrm{~mm}$ & range ( $26-32 \mathrm{~mm})$ & $22-31 \mathrm{~mm}$ \\
\hline $\begin{array}{l}\text { (LVEDd) } \\
\text { Doppler study }\end{array}$ & Severe MR & No MR & \\
\hline
\end{tabular}

\section{DISCUSSION}

Our patient presented with sign and symptoms of acute heart failure. We were led to suspect hypocalcaemia by the occurrence of seizure. The fact that she responded to the initiation of calcium and magnesium, treatment confirmed that dilated cardiomyopathy was secondary to hypocalcaemia. Few reports were available on hypocalcaemia-induced cardiomyopathy secondary to maternal vitamin $\mathrm{D}$ deficiency. From the available reports, it was observed that infantile hypocalcaemia migt have been related to maternal vitamin D deficiency (4). Vitamin D level of both the infant and the mother in our case was significantly low. The fact that the mother was house-bound, dark skinned and veiled outdoor showed her risk of vitamin D deficiency. It is recommended that pregnant mothers, particularly those who are dark skinned, veiled and those who do not get adequate dairy products in their diet should be given vitamin D suppl ementati on (5).

The mother in our case did not get vitamin D supplementation as the program is not available in Ethiopia. Our case was fed on exclusive breast feeding. It is also reported that exclusively breast-fed infants are at high risk of developing hypocalcaemia if the mothers are vitamin $\mathrm{D}$ deficient. The British Pediatric and Adolescent Bone Group recommended that exclusively breast-fed infants should receive Vitamin D supplements from soon after birth (6). The reported previous infant death in the same family was reportedly said to be due to pneumonia. Co-existence between cardiac failure and pneumonia was described by Sado indicating that excess pulmonary congestion in heart failure, acting as a nidus of infection leading to lower respiratory tract infection (7). The association between vitamin $\mathrm{D}$ deficiency and increased risk of lower respiratory tract 
infection has also been described in children (8). Many studies demonstrated a high prevalence of maternal vitamin $\mathrm{D}$ deficiency on rachitic children (9). Vitamin D deficiency induced dilated cardiomyopathy cases have also been reported commonly in association with rickets (2). Despite severe hypocalcaemia and severe Vitamin D deficiency, our patient did not manifest clinical features of rickets. The bone effect of severe hypocalcaemia secondary to Vitamin D deficiency in infants has been well studied (10). However, cardiac effect of such low level of calcium in neonates has been reported in few occasions. Soliman et al observed that younger infants below the age of six months have less clinical features of rickets compared to older children. They explains that these infants have less adaptability to Vitamin D deficiency as their Parathyroid hormone secretion in response to hypocalcaemia is low. They also have decreased skeletal response to Parathyroid hormone decreased bone mass (11). It has also been suggested that hypomagnesaemia can impair or induce resistance to parathyroid hormone secretion. In both of these situations, renal synthesis of 1,25(OH)2-vitamin D may be reduced. Magnesium deficiency induces skeletal resistance to the action of Parathyroid hormone (12). Thus, instead of finding florid rickets, one may get other forms of clinical manifestations like convulsions and/or dilated cardiomyopathy, for which our patient is the best example. She had a low level of serum magnesium which might have blunted the bone response to moderately increased Parathyroid hormone level. Lulseged from the same setting, two decades ago, reported cases of congestive heart failure in relation to rickets. However, it is not clear wether the congestive heart failure was due to cor-pulmonale or hypocalcaemia $(3,13,14,15)$. A similar case report presented from the gulf region on a 35-day old infant who developed respiratory distress. The first impression made was sepsis. However, detection of cardiomegaly on Chest X-ray with clinical features of heart failure prompted echocardiographic examination which confirmed dilated cardiomyopathy. The diagnosis of hypocalcaemia and vitamin D deficiency was also confirmed later when these tests were made. Similarly, the mother was severely vitamin $\mathrm{D}$ deficient who was not supplemented during pregnancy. The hemodynamic derangement was completely corrected after the deficiency state is treated in a similar fashion like our patient (16).

This Case report highlighted the importance of vitamin D deficiency in the diagnosis of dilated cardiomyopathy. To that effect we can teach the public on the importance of sunshine exposure not only to prevent rickets but also to prevent heart disease. We need to screen infants with dilated cardiomyopathy for hypocalcaemia if they are born to mothers with risk factors for vitamin D deficiency. This is because vitamin D deficiency has become public health problem. Early clinical suspicion and screening of at-risk mothers should also be considered by every physician. There is urgent need for welldesigned studies to determine the prevalence of vitamin $\mathrm{D}$ deficiency during pregnancy at least in mothers with risk factors.

\section{REFERENCES}

1. Lipscombe D. L-Type Calcium Channels Highs and New Lows. Circulation Research 2002; 90:933-5.

2. Hasim Olgun NC, Behzat Ozkan. A case of dilated cardiomyopathy due to nutritional vitamin D deficiency rickets.The Turkish Journal of Pediatrics 2003;45(2):152-4.

3. Sileshi. L. Severe Rickets in children's hospital in Addis Ababa. Ethiopian Med J 199028 (4) 175-81.

4. Dhaval K Chaudhari RG, Shaji Thomas John. Infant with hypocalcemia and Dilated Cardiomyopathy secondary to vitamin D deficiency. BMH Medical jornal 2015;2 (1):20-30.

5. Mozaffarian D, Hao T, Eric B, Rimm Sc B . Changes in diet and lifestyle and long-term weight gain in women and men. New England Journal of Medicine 2011;364(25): 2392-2404.

6. Memorial Hospital KE. Women and newborn health service . Maternal vitamin D deficiency. Perth Western Australia: NCCU 2016.

7. Mitch Blair DBJ, Dr Colin Michie. Guide for vitamin $\mathrm{D}$ in childhood. In Health. RCoPaC, editor 2013.

8. Sadoh WE OW. Underlying congenital heart disease in Nigerian children with 
pneumonia. African Health Sciences 2013 13 (3):607-12.

9. Esposito S LM. Vitamin D and respiratory tract infections in childhood. BMC Infect Dis. 2015 Oct 28;15:487. doi: 10.1186/s12879-015-1196-1.

10. Dawodu A, Absood G, Patel M, Agarwal M, Ezimokhai M, Abdulrazzaq $\mathrm{Y}$, et al. Biosocial factors affecting vitamin D status of women of childbearing age in the United Arab Emirates. JBiosoc Sci 199830 431-7. Tomar M RS, Shrivastava S. IndianPediatr 2010;47:781-3.

11. Soliman A1 SH, Alomar S, Shatla E, Ellithy $\mathrm{K}$, Bedair E. Clinical, biochemical, and radiological manifestations of vitamin $\mathrm{D}$ deficiency in newborns presented with hypocalcemia. Indian JEndocrionology andMetabolism, 2013;1 (4) ):697-703.
12. Litosch. G. Protein regulation of phospholipase $\mathrm{C}$ activity in a membranesolubilized system occurs through a Mg2(+)and time-dependent mechanism. $J$ Biol Chem 1991; 266(8):4764-71.

13. Belachew T NH, Getaneh T, W/ Mariam D, Getnet W. Calcium deficiency and causation of Rickets in Ethiopian children. East Afr Med J, 2005; 82(3):153-9.

14. Lulseged S1 FG. Vitamin D deficiency rickets: Socio-demographic and clinical risk factors in children seen at a referral hospital in Addis Ababa. East Afr Med J 1999 76;(8):457- 61.

15. A AAMHA. Newborn with Dilated Cardiomyopathy Secondary to Vitamin D Deficiency Hindawi. 2012;2012(5):5 pages. 